\title{
Estimating Dynamic Ultimate Tensile Strength from Instrumented Charpy Data*
}

* Contribution of NIST, an agency of the US government; not subject to copyright in the United States. 
Enrico Lucon ${ }^{\mathrm{a}}$

${ }^{a}$ National Institute of Standards and Technology, 325 Broadway, Boulder CO 80303 (US).

E-mail: enrico.lucon@ nist.gov. Tel: +1-303-497-4750. Fax: +1-303-497-5030.

\begin{abstract}
Instrumented Charpy test data have often been used to obtain estimates of various mechanical properties under elevated loading rates, such as dynamic yield properties. A widely used relationship between Charpy general yield force and dynamic yield strength was originally proposed by Server in 1978. This same relationship, however, cannot be used for estimating the dynamic (ultimate) tensile strength from the Charpy maximum force, since it relies on the ratio between shear and tensile stress, which at general yield is different than at maximum force. In the study described in this paper, we modified Server's relationship in order to obtain reliable, and possibly conservative, estimates of dynamic ultimate tensile strength from the maximum force measured in an instrumented Charpy test. Once more experimental data has been accumulated, the results of this investigation might have significant implications for the revision of fracture mechanics test standards which utilize dynamic ultimate tensile properties for the qualification/validation of fracture toughness tests conducted at elevated loading rates.
\end{abstract}

Keywords: Charpy impact test; dynamic ultimate tensile testing; strain rate; tensile behavior; yield strength.

\title{
1. Introduction
}

Instrumented impact testing is often considered to be a relatively recent technical 
development of Charpy testing, even though the earliest known paper dealing with force measurements during an impact test [1] actually predates the first pendulum machine publication [2] by one year. In fact, instrumented Charpy testing started to gain popularity in the technical community in the early 1920s, when it was still considered a sort of laboratory curiosity [3]. It was however in the 1950 s and 1960s that the scientific community recognized that a more accurate understanding of the dynamic fracture process could be achieved only by instrumenting the pendulum machine, and specifically by applying strain-gages to the striker in order to determine force/time test records. From force and time measurements, it was then possible to derive specimen deflection and ultimately obtain the energy absorbed by the specimen during the fracture process.

The analysis of an instrumented Charpy test consists in the determination of characteristic time, force, displacement, and absorbed energy values corresponding to general yield, maximum force, initiation of unstable fracture, arrest of unstable fracture, and test termination (Figure 1).

These events are not identifiable in all tests. Fully brittle specimens, representative of lower shelf behavior, do not exhibit general yield, and typically maximum force coincides with the initiation of unstable fracture. Furthermore, the force at crack arrest is normally equal to zero. Fully ductile specimens, representative of upper shelf behavior, do not exhibit unstable fracture or crack arrest. 


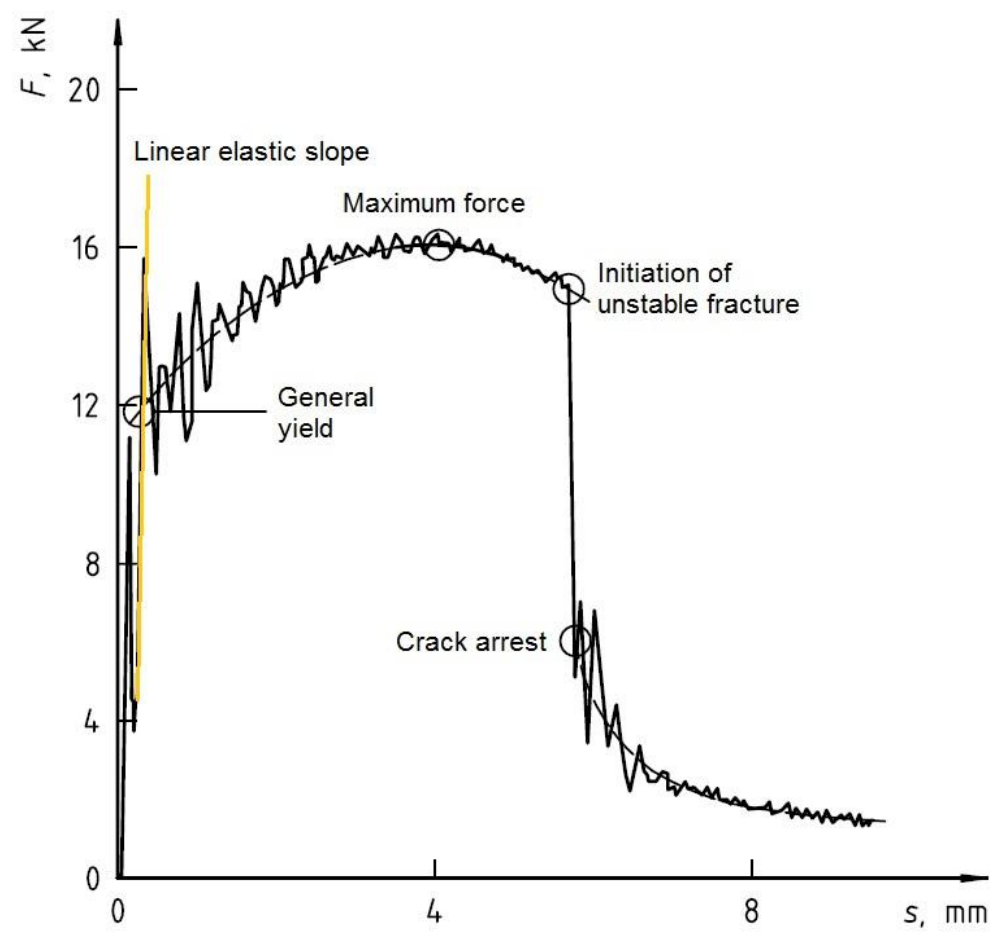

Figure 1 - Example of instrumented Charpy test record for a specimen tested in ductile-to-brittle transition regime.

In laboratory practice, characteristic force and absorbed energy values are used for several types of analyses, some of which are listed below.

- Forces and absorbed energies at unstable fracture allow calculating dynamic toughness in the ductile-to-brittle transition region (ASTM E1921, Annex A1).

- The whole force/deflection test record can be used to assess dynamic fracture toughness in the fully plastic (upper shelf) regime (ASTM E1820, Annex A17).

- Characteristic instrumented forces are utilized to study the flow and fracture behavior of nuclear reactor pressure vessel steels [4]; particularly, alternative physically-based index temperatures have been defined to characterize ductile-to-brittle transition and irradiationinduced embrittlement.

- The proportion of ductile fracture surface (Shear Fracture Appearance, SFA) can be effectively estimated using empirical relationships established between $S F A$ and characteristic 
force values [5-9]. Four empirical formulae are included in both ISO 14556 and ASTM E2298.

Another important application of the characteristic force at general yield $\left(F_{g y}\right)$, proposed by Server in 1978 [10], is the estimation of dynamic yield strength $\left(\sigma_{Y S d}\right)$ based on $F_{g y}$ values. The dynamic yield strength of a material is of particular importance for loading-rate sensitive materials such as low strength steels. Typical applications of $\sigma_{Y S d}$ values include the characterization of steels for the automotive and aircraft industries, structural assessments of pressure vessels, and other circumstances where high loading rates and impact events are possible during operation.

\section{Estimation of dynamic yield strength from the force at general yield}

On an instrumented force/time or force/displacement record (Figure 1), general yield (GY) corresponds to the point where plastic yielding spreads across the whole unnotched ligament of the specimen. At general yield, the propagation of the plastic hinges across the specimen ligament occurs rather suddenly, even though small plastic strains extending across the ligament (less than $1 \%$ ) can be detected even before GY [11].

In [10], Server applied a slip-line fields solution $[12,13]$ to describe the form of the plane strain plastic zone below a notch, and included the effect of the shape of the Charpy striker on both Charpy V-notch and precracked specimens. Thus, he obtained estimates of high loading-rate yield strength values.

A key parameter in Server's investigation was the constraint factor at general yield $C_{G Y}$, i.e., the ratio between $F_{g y}$ and the force required to yield an unnotched specimen having the same cross section as the Charpy (notched) specimen. The constraint factor was defined as 


$$
C_{G Y}=\frac{2 M_{G Y}}{\tau_{G Y}(W-a)^{2}},
$$

where: $M_{G Y}=$ applied bending moment at general yield per unit thickness,

$\tau_{G Y}=$ shear yield strength,

$W=$ specimen width, and

$a=$ notch depth (or crack size for a precracked specimen).

The ratio between shear and tensile strength in metals is expressed by a number ranging from 0.5 to 1.3 , depending on the specific material and whether one considers yield or ultimate strength. More specifically, for ultimate tensile strengths values ranging between 0.65 (aluminum) and 1.3 (cast iron) have been reported [14].

A yield criterion relates shear and tensile stress at the onset of yielding in a metal. The most commonly used was formulated by J. C. Maxwell in 1865 , but is generally attributed to R. von Mises [15]. It is expressed as

$$
\tau_{G Y}=\frac{\sigma_{G Y}}{\sqrt{3}}=0.577 \sigma_{G Y} \cdot
$$

A mathematically simpler criterion had been proposed by H. E. Tresca in 1864 [16],

$$
\tau_{G Y}=\frac{\sigma_{G Y}}{2}=0.5 \sigma_{G Y}
$$

In 1964, Fearnehough and Hoy [17] suggested an intermediate criterion between Tresca and Von Mises in the specific case of instrumented Charpy tests:

$$
\tau_{G Y}=\frac{\sigma_{G Y}}{1.866}=0.536 \sigma_{G Y}
$$

Eq. 4 was found by Chaouadi and Fabry [4] to provide the best agreement between yield strength values measured from dynamic ultimate tensile tests and estimated from instrumented impact tests, and this criterion has been adopted in this work. 
Substituting eq. 4 in eq. 1 and solving for $\sigma_{G Y}$ gives

$$
\sigma_{G Y}=\frac{3.732 M_{G Y}}{C_{G Y}(W-a)^{2}}
$$

For a Charpy-type specimen loaded in 3-point-bending with a span-to-width ratio of 4 , the bending moment per unit thickness is given by

$$
M=\frac{F W}{B},
$$

with $B=$ specimen thickness. Replacing $M_{G Y}$ in eq. 5 , we obtain

$$
\sigma_{G Y}=\frac{3.732 F_{G Y} W}{C_{G Y} B(W-a)^{2}}
$$

The constraint factor $C_{G Y}$ depends on the shape of the indenter (i.e., the radius of striking edge) and the root radius of the notch $[12,13,18]$. Its values for different strikers (striking edge radius $2 \mathrm{~mm}$ or $8 \mathrm{~mm}$ ) and Charpy specimen types ( $\mathrm{V}$-notched and precracked) are given in Table 1.

Table 1 - Values of the constraint factor $C_{G Y}$ at general yield for different striker and specimen types.

\begin{tabular}{ccc}
$\begin{array}{c}\text { Striking edge } \\
\text { radius (mm) }\end{array}$ & $\begin{array}{c}\text { Specimen } \\
\text { type }\end{array}$ & $\boldsymbol{C}_{\boldsymbol{G Y}}$ \\
\hline 2 & V-notched & 1.274 \\
\cline { 2 - 3 } 2 & Precracked & 1.279 \\
\hline \multirow{2}{*}{8} & V-notched & 1.336 \\
\cline { 2 - 3 } & Precracked & 1.402 \\
\hline
\end{tabular}

In this investigation, we tested $\mathrm{V}$-notched specimens by means of a pendulum machine equipped with an instrumented striker conforming to ASTM E23, and therefore $C_{G Y}=1.336$ according to Table 1. We now define the following dimensionless parameter

$$
\eta_{G Y}=\frac{3.732}{C_{G Y}}=2.793
$$


which simultaneously accounts for the ratio between shear and tensile stress and the constraint conditions at general yield. Eq. 7 accordingly becomes

$$
\sigma_{G Y}=\frac{\eta_{\mathrm{GY}} F_{G Y} W}{B(W-a)^{2}}
$$

Based on eq. 8 and assuming nominal specimen dimensions ( $W=B=10 \mathrm{~mm}, a=2 \mathrm{~mm})$,

$$
\sigma_{G Y}=43.65 F_{G Y} \quad,
$$

with $F_{G Y}$ in $\mathrm{kN}$ and $\sigma_{G Y}$ in $\mathrm{MPa} . \sigma_{G Y}$ is an estimate of the dynamic yield strength $\sigma_{Y S d}$ of the material at the strain rate experienced by the uncracked ligament of the Charpy specimen during the instrumented test.

\section{Materials and experiments}

Eight steels corresponding to a wide range of tensile and fracture properties have been tested in this work. Their chemical composition and basic mechanical properties are listed in Table 2 and Table 3 respectively.

\begin{tabular}{|c|c|c|c|c|c|c|c|c|c|c|c|}
\hline Steel & $\mathbf{C}$ & Mn & $\mathbf{S}$ & $\mathbf{P}$ & $\mathbf{S i}$ & $\mathrm{Cr}$ & $\mathbf{N i}$ & Mo & $\mathbf{C u}$ & $\mathbf{V}$ & $\mathbf{N b}$ \\
\hline A709 & 0.13 & 1.05 & 0.030 & 0.013 & 0.33 & 0.50 & 0.08 & 0.03 & 0.32 & 0.022 & 0.003 \\
\hline 73W & 0.098 & 1.56 & 0.005 & 0.005 & & 0.25 & 0.60 & 0.58 & 0.31 & 0.003 & \\
\hline 2205 Duplex SS $^{2}$ & $\leq 0.03$ & $\leq 2.0$ & $\leq 0.015$ & $\leq 0.030$ & $\leq 1.0$ & 22 & 5 & 3.2 & & & \\
\hline A36 & 0.049 & 0.58 & 0.008 & 0.009 & 0.27 & 0.75 & 0.86 & 0.19 & 1.16 & 0.003 & 0.036 \\
\hline X100 & 0.07 & 1.83 & 0.005 & 0.005 & 0.11 & 0.03 & 0.52 & 0.27 & 0.30 & & 0.027 \\
\hline $\begin{array}{l}\text { 4340-LL } \\
\text { 4340-HH }\end{array}$ & 0.4 & 0.66 & 0.001 & 0.004 & 0.28 & 0.83 & 1.77 & 0.28 & & & \\
\hline T-200 ${ }^{2}$ & $\leq 0.01$ & $\leq 0.01$ & $\leq 0.01$ & $\leq 0.01$ & $\leq 0.01$ & & 18.5 & 3.0 & & & \\
\hline
\end{tabular}

Table 2 - Chemical composition of the investigated steels (weight \%).

\footnotetext{
${ }^{2}$ Nominal chemical composition.
} 
Table 3 - Basic mechanical properties of the investigated steels.

\begin{tabular}{cllll}
\hline Steel & $\begin{array}{c}\sigma_{\mathbf{Y S}} \\
(\mathbf{M P a})\end{array}$ & $\begin{array}{c}\boldsymbol{\sigma}_{\boldsymbol{T S}} \\
(\mathbf{M P a})\end{array}$ & $\begin{array}{c}\boldsymbol{\varepsilon}_{\boldsymbol{t}} \\
(\boldsymbol{\%})\end{array}$ & $\begin{array}{c}\boldsymbol{K} \boldsymbol{V} \\
(\boldsymbol{\%})\end{array}$ \\
\hline A709 & 378 & 583 & 22 & 123 \\
\hline $\mathbf{7 3 W}$ & 496 & 674 & 19 & 95 \\
\hline $\mathbf{2 2 0 5}$ Duplex SS & 588 & 860 & 25 & 356 \\
\hline A36 & 259 & 423 & 36 & 193 \\
\hline X100 (or. L) & 756 & 870 & 6 & 441 \\
\hline X100 (or. T) & 887 & 906 & 14 & 255 \\
\hline $\mathbf{4 3 4 0 - L L}$ & 1348 & 1529 & 5 & 21 \\
\hline $\mathbf{4 3 4 0 - H H}$ & 909 & 1050 & 21 & 110 \\
\hline T-200 (SH-37) & 930 & 1012 & 22 & 249 \\
\hline T-200 (SH-38) & 1012 & 1170 & 17 & 173 \\
\hline
\end{tabular}

LEGEND $-\sigma_{Y S}, \sigma_{T S}, \varepsilon_{t}$ : yield strength, tensile strength, and elongation at fracture at quasi-static strain rates $\left(10^{-4} \mathrm{~s}^{-1}\right.$ to $\left.10^{-3} \mathrm{~s}^{-1}\right) . K V=$ Charpy energy at room temperature.

Based on the information provided in Table 3, the steels investigated cover a wide range of basic mechanical properties, namely:

- $\quad$ room temperature quasi-static yield strengths between $259 \mathrm{MPa}$ and $1348 \mathrm{MPa}$;

- $\quad$ room temperature quasi-static tensile strengths between $423 \mathrm{MPa}$ and $1529 \mathrm{MPa}$;

- $\quad$ room temperature quasi-static elongations at fracture between $5 \%$ and $36 \%$;

- room temperature Charpy energies between $21 \mathrm{~J}$ and $441 \mathrm{~J}$.

\subsection{Tensile tests}

Tensile testing on the investigated steels was carried out partly at Colorado School of Mines (CSM, Golden, Colorado) and partly at NIST in Boulder, Colorado. All tests were conducted in actuator displacement control (i.e., at a constant speed of the machine actuator), but CSM tests on A36, X100 and SH-37 were performed without extensometer, whereas specimens at NIST (for all the remaining materials) were instrumented with an axial extensometer with sufficient travel $(1 \mathrm{in}=25.4 \mathrm{~mm})$ to cover specimen elongation up to fracture.

All testing was performed at room temperature $\left(21{ }^{\circ} \mathrm{C} \pm 2{ }^{\circ} \mathrm{C}\right)$, using ASTM E8/E8M- 
type specimens with round cross section and diameter of the gage section $D=2.5 \mathrm{~mm}(\mathrm{SH}-37)$, $D=4 \mathrm{~mm}$ (X100 and A36), or $D=3 \mathrm{~mm}$ (all the remaining materials). In order to effectively characterize the strain rate dependence of the materials, tensile tests were performed at multiple strain rates ranging from $10^{-4} \mathrm{~s}^{-1}$ to $10^{1} \mathrm{~s}^{-1}$.

\subsection{Instrumented Charpy tests}

All the instrumented Charpy tests were performed with a large-capacity impact machine (potential energy $=953.56 \mathrm{~J}$, impact velocity $=5.47 \mathrm{~m} / \mathrm{s}$ ). The machine was equipped with an instrumented striker conforming to ASTM E23-12b (radius of the striking edge $=8 \mathrm{~mm}$ ). All tests were performed at room temperature, and most of the investigated steels exhibited fully ductile behavior (upper shelf conditions). However, three materials (4340-LL, 73W, and A709) presented unstable crack propagation events, indicating that for these steels $21{ }^{\circ} \mathrm{C}$ lies within the ductile-to-brittle transition region.

\section{Results}

\subsection{Establishment of the uniaxial strain rates corresponding to the Charpy test}

By comparing the results of the tensile tests performed at different strain rates to the dynamic yield strength values estimated from the instrumented Charpy tests by means of eq. 10, we obtained the values of equivalent Charpy strain rate shown in Table 4.

The results given in Table 4 show that the equivalent strain rate for a Charpy test can be very different from material to material. For the ten materials considered in this work, the equivalent Charpy strain rates fall in a range from $10^{-1} \mathrm{~s}^{-1}$ to $10^{4} \mathrm{~s}^{-1}$. 
Table 4 - Test conditions and resulting equivalent Charpy strain rates at general yield for the steels investigated.

\begin{tabular}{ccccc}
\hline Steel & $\begin{array}{c}\text { Number of } \\
\text { tensile tests }\end{array}$ & $\begin{array}{c}\text { Strain rate } \\
\text { range }\left(\mathbf{s}^{-1}\right)\end{array}$ & $\begin{array}{c}\text { Number of } \\
\text { Charpy tests }\end{array}$ & $\begin{array}{c}\bullet \\
\boldsymbol{\varepsilon}_{Y S, C V} \\
\left(\mathbf{s}^{-1}\right)\end{array}$ \\
\hline A709 & 6 & $1 \times 10^{-4} \div 1.52$ & 3 & 6.22 \\
\hline $\mathbf{7 3 W}$ & 6 & $1 \times 10^{-4} \div 1.53$ & 3 & 1.44 \\
\hline $\mathbf{2 2 0 5}$ Duplex SS & 5 & $1 \times 10^{-4} \div 1.54$ & 2 & 81.09 \\
\hline A36 & 4 & $1.33 \times 10^{-2} \div 13.4$ & 5 & 131.31 \\
\hline X100 (or. L) & 5 & $1.34 \times 10^{-3} \div 13.4$ & 5 & 1111.08 \\
\hline X100 (or. T) & 5 & $1.34 \times 10^{-2} \div 13.4$ & 5 & 0.74 \\
\hline $\mathbf{4 3 4 0 - L L}$ & 5 & $1 \times 10^{-4} \div 1.59$ & 5 & 1.95 \\
\hline $\mathbf{4 3 4 0 - H H}$ & 6 & $1 \times 10^{-4} \div 1.57$ & 5 & 9.35 \\
\hline T-200 (SH-37) & 4 & $4.89 \times 10^{-4} \div 4.91$ & 5 & 24.99 \\
\hline T-200 (SH-38) & 6 & $1 \times 10^{-4} \div 1.57$ & 5 & 0.54 \\
\hline
\end{tabular}

\subsection{Estimation of dynamic ultimate tensile strength from instrumented Charpy tests}

The use of eq. 9 (or eq. 10) with the maximum force $F_{m}$ in place of $F_{G Y}$ in order to estimate values of dynamic ultimate tensile strength, $\sigma_{T S d}$, cannot be expected to yield acceptable results (see Figure 2 with data from A709 as an example), because both the ratio between shear and tensile stress and the constraint factor at maximum force are different than at general yield. For steels, engineering handbooks normally provide an approximate ratio of 0.75 between ultimate shear strength and ultimate tensile strength, as opposed to an approximate ratio of 0.58 between yield shear strength and yield tensile strength [14]. Published values of the constraint factor at maximum force $C_{F m}$ are not available.

In order to empirically derive a relationship similar to eq. 9 , which could be used to estimate dynamic ultimate tensile strength values from Charpy maximum forces, we followed the procedure described below. The procedure will be illustrated with practical examples for one of the investigated steels (A709), as depicted in Figure 2. 


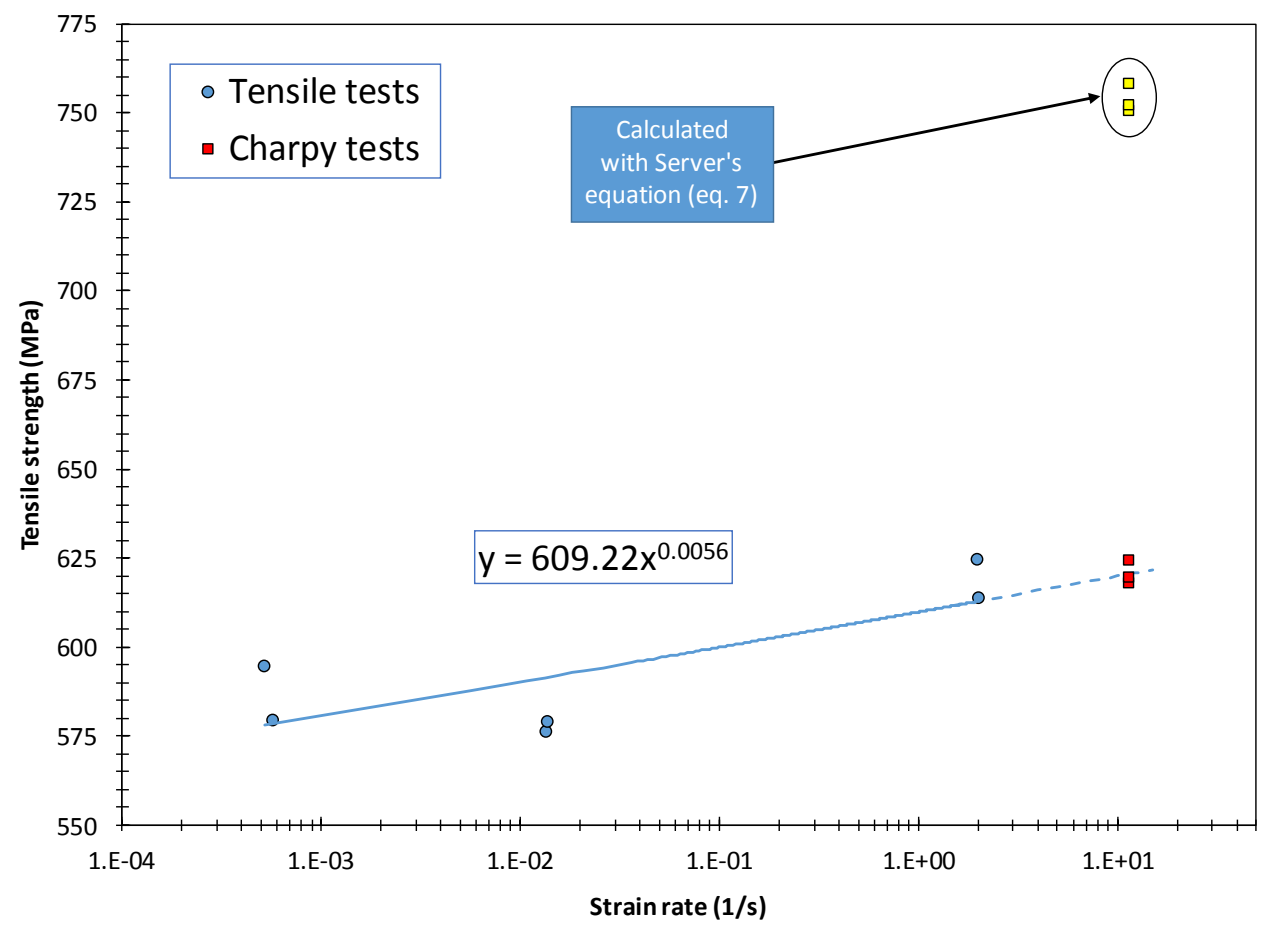

Figure 2 - Values of tensile strength for A709 measured from tensile tests (blue symbols) and estimated from instrumented Charpy tests (red symbols). Illustration of the procedure followed to derive an empirical value of $\eta_{F m}$ for the steels investigated.

(1) The values of tensile strength, $\sigma_{T S}$, obtained from the tensile tests performed were plotted as a function of strain rate. The strain rate associated to $\sigma_{T S}$ was designated $\dot{\varepsilon}_{T S}$.

(2) The values of $\sigma_{T S}$ from the tensile tests were fitted using a power law of the form

$$
\boldsymbol{\sigma}_{T S}=A_{T S}\left(\dot{\boldsymbol{\varepsilon}}_{T S}\right)^{m_{T S}}
$$

where $A_{T S}$ and $m_{T S}$ are fitting coefficients obtained by least squares regression. The exponent $m_{T S}$ represents the strain-rate sensitivity of the material's tensile strength (Table 5). 
Table 5 - Strain-rate sensitivities of tensile strengths measured for the steels investigated.

\begin{tabular}{cc}
\hline Steel & $\boldsymbol{m}_{T S}$ \\
\hline A709 & 0.006 \\
\hline $\mathbf{7 3 W}$ & 0.007 \\
\hline 2205 Duplex SS & 0.006 \\
\hline A36 & 0.019 \\
\hline X100 (or. L) & 0.007 \\
\hline X100 (or. T) & 0.008 \\
\hline $\mathbf{4 3 4 0 - L L}$ & 0.001 \\
\hline $\mathbf{4 3 4 0 - H H}$ & 0.005 \\
\hline T-200 (SH-37) & 0.010 \\
\hline T-200 (SH-38) & 0.005 \\
\hline
\end{tabular}

(3) In order to establish the equivalent strain rate corresponding to the maximum force in the Charpy tests $\left(\dot{\varepsilon}_{T S, F m}\right)$, we have adjusted the previously calculated strain rates at general yield $\left(\dot{\varepsilon}_{T S, G Y}\right.$, see Table 4) by a correction factor that accounts for the fact that the hammer speed decreases slightly from general yield to maximum force. The equivalent strain rate is proportional to the deflection rate, which is in turn proportional to the hammer speed. The relationship used to correct the equivalent strain rates at general yield is therefore

$$
\dot{\boldsymbol{\varepsilon}}_{T S, F m}=\frac{v_{G Y}}{v_{F m}} \cdot \dot{\boldsymbol{\varepsilon}}_{T S, G Y}
$$

where $v_{G Y}$ and $v_{F m}$ are the hammer speeds at general yield and at maximum force, respectively. For the ten materials investigated, correction factors vary between 0.90 and 0.99 (Table 6). 
Table 6 - Correction factors for the investigated materials.

\begin{tabular}{cc}
\hline & $\dot{\boldsymbol{\varepsilon}}_{T S, F m}$ \\
\cline { 2 - 2 } Steel & $\dot{\boldsymbol{\varepsilon}}_{T S, G Y}$ \\
\hline A709 & 0.97 \\
\hline $\mathbf{7 3 W}$ & 0.97 \\
\hline 2205 Duplex SS & 0.94 \\
\hline A36 & 0.90 \\
\hline X100 (or. L) & 0.96 \\
\hline X100 (or. $\mathbf{T})$ & 0.96 \\
\hline $\mathbf{4 3 4 0}$-LL & 0.99 \\
\hline $\mathbf{4 3 4 0 - H H}$ & 0.98 \\
\hline T-200 (SH-37) & 0.97 \\
\hline T-200 (SH-38) & 0.97 \\
\hline
\end{tabular}

(4) An estimate of the dynamic ultimate tensile strength can be obtained by assuming a relationship of the same form as the one proposed by Server [10] for the dynamic yield strength:

$$
\sigma_{T S d}=\frac{\eta_{F m} F_{m} W}{B(W-a)^{2}}
$$

where the empirical factor $\eta_{F m}$ accounts for both the ratio between shear and tensile stress, and the constraint factor at maximum force. The value of $\eta_{F m}$ in eq. 13 has been calculated, for each one of the investigated materials, by minimizing the sum of residuals between the values from eq. 13 and the values from the power law regression of eq. 11. The strain rate associated to each Charpy test was obtained from eq. 12 . The values of $\eta_{F m}$ obtained for the ten investigated materials are listed in Table 7, while an overview of the analyses conducted on the remaining materials is presented in Figure 3. The average value of $\eta_{F m}=2.385$ should be compared with $\eta_{G Y}=2.793$ from eq. 8 . 

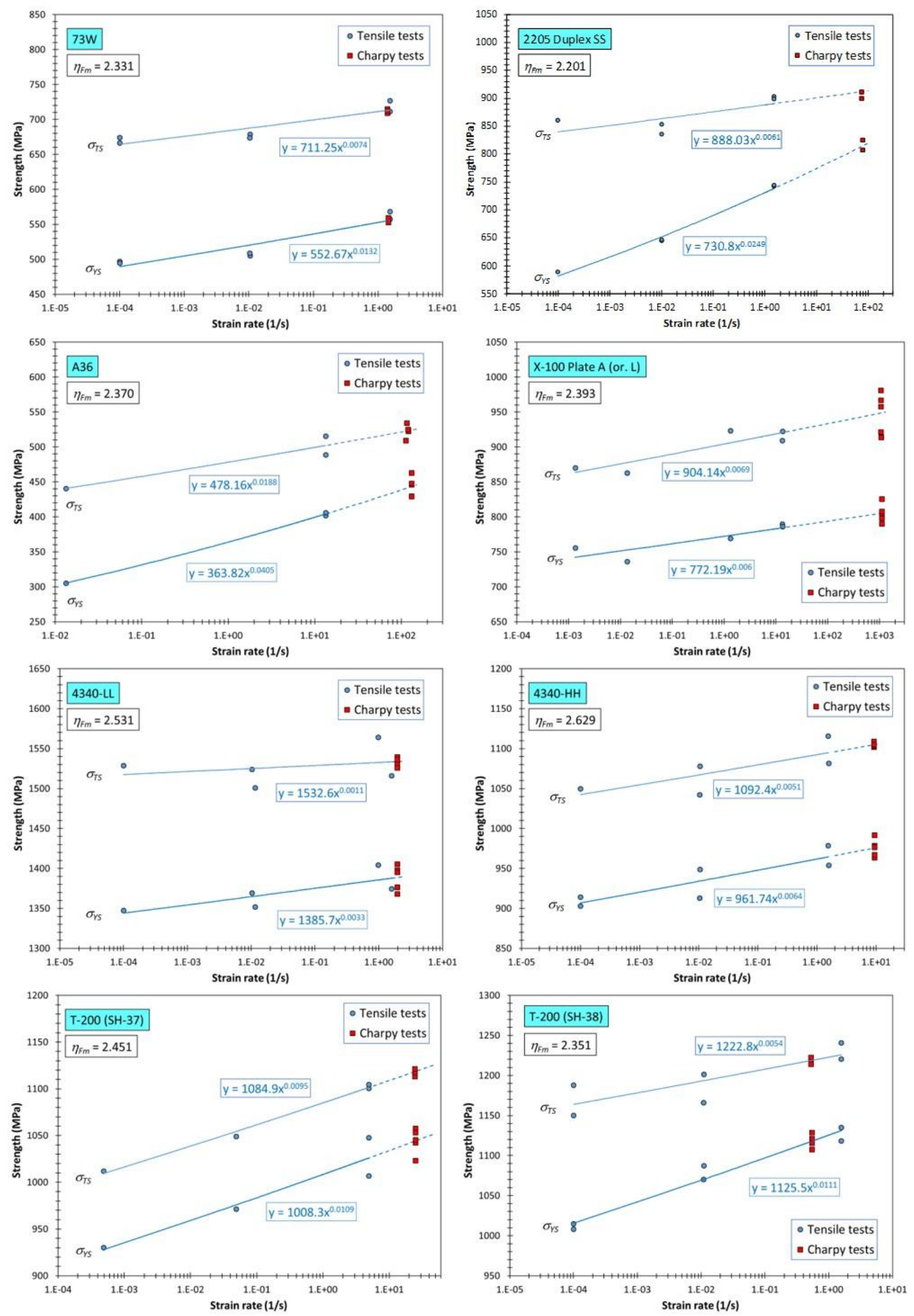

Figure 3 -Overview of the analyses performed on the remaining materials. NOTE: for the sake of clarity, in the case of X100 Plate A, only the results for the L orientation are shown. 
Table 7 - Values of $\eta_{F m}$ calculated for the investigated steels, with overall average value and standard deviation.

\begin{tabular}{|c|c|}
\hline Steel & $\eta_{F m}$ \\
\hline A709 & 2.283 \\
\hline 73W & 2.331 \\
\hline 2205 Duplex SS & 2.201 \\
\hline A36 & 2.370 \\
\hline X100 (or. L) & 2.393 \\
\hline X100 (or. T) & 2.307 \\
\hline 4340-LL & 2.531 \\
\hline 4340-HH & 2.629 \\
\hline T-200 (SH-37) & 2.451 \\
\hline T-200 (SH-38) & 2.351 \\
\hline Average & 2.385 \\
\hline Standard dev. & $0.125(5 \%)$ \\
\hline
\end{tabular}

The empirical relationship obtained in this investigation for estimating dynamic ultimate tensile strength from the maximum force in an instrumented tensile test is therefore

$$
\sigma_{T S d}=\frac{2.385 F_{m} W}{B(W-a)^{2}},
$$

and is valid for the following two conditions:

- radius of the striking edge $=8 \mathrm{~mm}$;

- Charpy-type notched specimen.

Assuming nominal dimensions for a standard Charpy specimen ( $W=B=10 \mathrm{~mm}, a=2$

$\mathrm{mm})$, eq. 14 reduces to

$$
\sigma_{T S d}=37.26 F_{m}
$$

with $F_{m}$ expressed in $\mathrm{kN}$ and $\sigma_{T S d}$ expressed in $\mathrm{MPa}$.

For a conservative estimate of $\sigma_{T S d}$, we can use the average value of $\eta_{F m}$ in Table 7 minus two standard deviations, and eq. 15 becomes

$$
\sigma_{T S d}=37.15 F_{m}
$$


The values of $\eta_{F m}$ in Table 7 have been found to be moderately correlated with the Charpy energy $K V(r=-0.430$, Figure 4$)$ and with the quasi-static RT tensile strength $\sigma_{T S}$ $(r=0.530$, Figure 5). The relatively small size of the available database and the limited amount of correlation found in Figure 4 and Figure 5 do not, in our opinion, justify replacing the constants in eqs. 13,14 and 15 with linear functions of $K V$ or $\sigma_{T S}$.

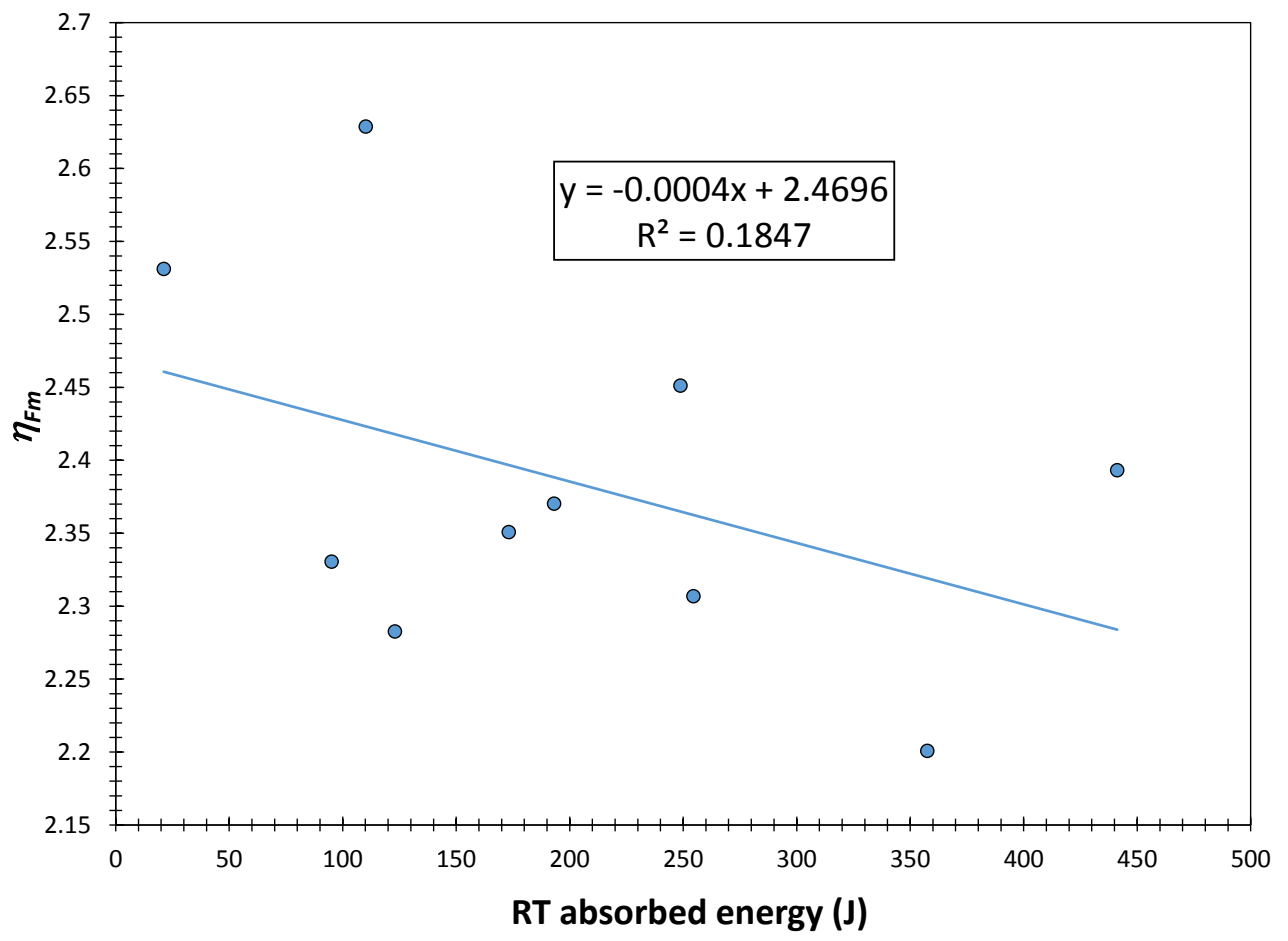

Figure 4 - Correlation between $\eta_{F m}$ and $K V$. 


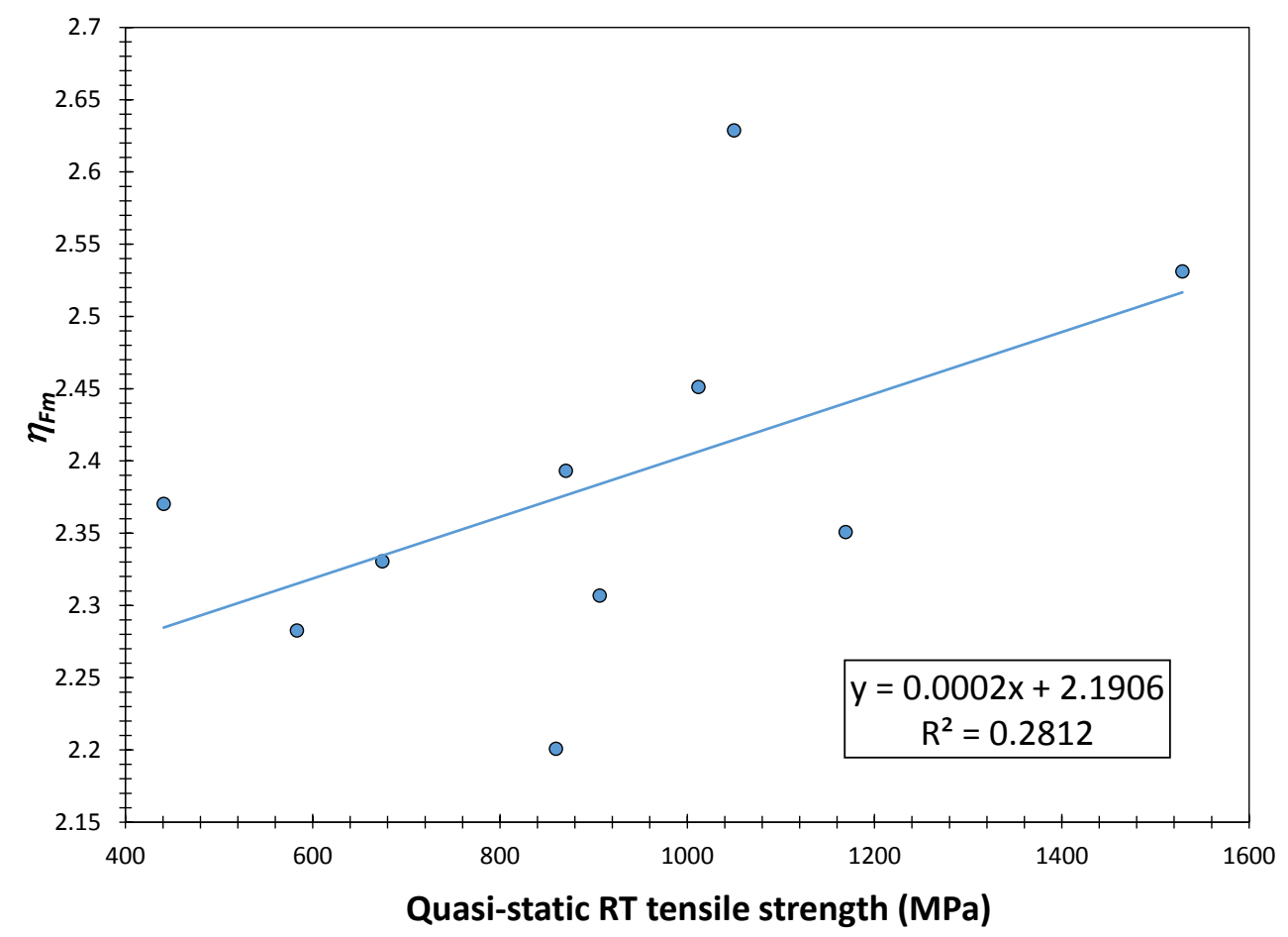

Figure 5 - Correlation between $\eta_{F m}$ and RT quasi-static tensile strength.

\section{Conclusions}

An investigation was conducted at NIST in Boulder Colorado, consisting of tensile tests performed at different strain rates and instrumented Charpy tests on specimens from 10 different materials, covering a wide range of mechanical properties (quasi-static yield strengths between $378 \mathrm{MPa}$ and $1348 \mathrm{MPa}$, Charpy energies between $21 \mathrm{~J}$ and $441 \mathrm{~J}$ ).

The results obtained were used to establish an empirical relationship between dynamic (ultimate) tensile strength and maximum force in an instrumented Charpy test, which can be used in a similar way to a well-established relationship between dynamic yield strength and Charpy force at general yield, published by Server in 1978.

Server's relationship accounted for the relationship between shear stress and tensile (uniaxial) stress at general yield, which is different from the relationship at maximum force, 
where tensile strength is established. As a consequence, the use of Server's equation at maximum force causes a gross, non-conservative estimate of the dynamic ultimate tensile strength and should be avoided.

By minimizing the residuals between Charpy-based estimates and a power-law regression of tensile strength values obtained from tensile tests, we adapted Server's equation to account for the ratio between shear and tensile stresses at maximum force. The obtained relationship is currently strictly applicable to the range of materials and mechanical properties that have been investigated in our work. However, given the wide range of steel types and tensile strengths that we have considered, the approach presented here shows promise for providing reliable (or conservative) Charpy-based estimates of dynamic ultimate tensile strength. Once the results will be confirmed by additional experimental data (other materials and other test temperatures), we could consider submitting including the new correlation into future revisions of relevant ASTM and ISO test standards.

\section{Acknowledgments}

The tensile tests on A36, SH-37 and X100 were conducted by NIST in collaboration with Andrew Douglas and Kip Findley from Colorado School of Mines (Golden, CO). Their collaboration is gratefully acknowledged, as well as the many fruitful technical discussions.

\section{References}

[1] D.W. Dunn, A Photographic Impact Testing Machine for Measuring the Varying Intensity of an Impulsive Force, J. Frankl. Inst. CXLIV(5) (1897) 321-348.

[2] S.B. Russell, Experiments with a New Machine for Testing Materials by Impact, Trans. Am. Soc. Civ. Eng. 39, 826 (1898) 237-250. 
[3] M.P. Manahan, T.A. Siewert, The History of Instrumented Impact Testing, J. ASTM Int., 3 (2) (2006).

[4] R. Chaouadi, A. Fabry, On the utilization of the instrumented Charpy impact test for characterizing the flow and fracture behavior of reactor pressure vessel steels, in: D. François, A. Pineau (Eds.), From Charpy to Present Impact Testing, ESIS Publication 30, Elsevier Science, 2002, 103-117.

[5] Tests to Determine Onset of Upper-Shelf Energy, Weld J. (Miami), 60 (5) (1981), 85-91.

[6] R.K. Nanstad, R.G. Berggren, Irradiation Effects on Charpy Impact and Tensile Properties of Low Upper-Shelf Welds, HSSI Series 2, Vol. 3, NUREG/CR-5696 (ORNL/TM-11804), 1991.

[7] A. Fabry, E. van Walle, R. Chaouadi, J-P. Wannijn, A. Verstrepen, J.-L. Puzzolante, Th. Van Ransbeeck, J. Van de Velde, RPV Steel Embrittlement: Damage Modeling and Micromechanics in an Engineering Perspective, IAEA/OECD Specialists’ Meeting on Irradiation Embrittlement and Optimization of Annealing, Paris (France), 1993.

[8] R.K. Nanstad, M.A. Sokolov, Charpy Impact Test Results on Five Materials and NIST Verification Specimens Using Instrumented 2-mm and 8-mm Strikers, in: T.A. Siewert, A.K. Schmieder (Eds.), Pendulum Impact Machines: Procedures and Specimens for Verification, ASTM STP 1248, American Society for Testing and Materials, Philadelphia, $1995,111-139$.

[9] K. Wallin, P. Nevasmaa, T. Planman, M. Valo, Evolution of the Charpy-V Test from a Quality Control Test to a Materials Evaluation Tool for structural Integrity Assessment, in: E. van Walle (Ed.), Evaluating Materials Properties by Dynamic Testing, Mechanical Engineering Publications, London, 1996. 
[10] W.L. Server, General Yielding of Charpy V-Notch and Precracked Charpy Specimens, J. Eng. Mat. Technol. 100 (2) (1978) 183-188.

[11] T.R. Wilshaw, Deformation and Fracture of Mild Steel Charpy Specimens, J. Iron and Steel Inst. 204 (1966) 936-942.

[12] A.P. Green, B.B. Hundy, Initial Plastic Yielding in Notch Bend Tests, J. Mech. Phys. Solids 4 (1956) 128-144.

[13] A.P. Green, Plastic Yielding of Notched Bars Due to Bending, Q. J. Mech. Appl. Math. 6, Part 2 (1953) 223-239.

[14] A.D. Deutschman, W.A. Michels, C.E. Wilson, Machine Design Theory and Practice, MacMillan, 1975.

[15] R. von Mises, Mechanik der festen Körper im plastisch deformablen Zust, in: Nachrichten von der Gesellschaft der Wissenschaften zu Göttingen, Mathematisch-Physikalische Klasse, 1 (1913) 582-592.

[16] H. Tresca, Mémoire sur l'écoulement des corps solides soumis à des fortes pressions, C.R. Acad. Sci. Paris 59 (1864) 754-758.

[17] G.D. Fearnehough, C.J. Hoy, Mechanism of Deformation and Fracture in Charpy Test as Revealed by Dynamic Recording of Impact Loads, J. Iron Steel Inst. 202 (1964) 912-921.

[18] G. Lianis, H. Ford, Plastic Yielding of Single Notched Bars Due to Bending, J. Mech. Phys. Solids 7 (1958) 1-21.

[19] K. Pearson, Notes on regression and inheritance in the case of two parents, in: Proc. of the Royal Society of London 58 (1895) 240-242. 


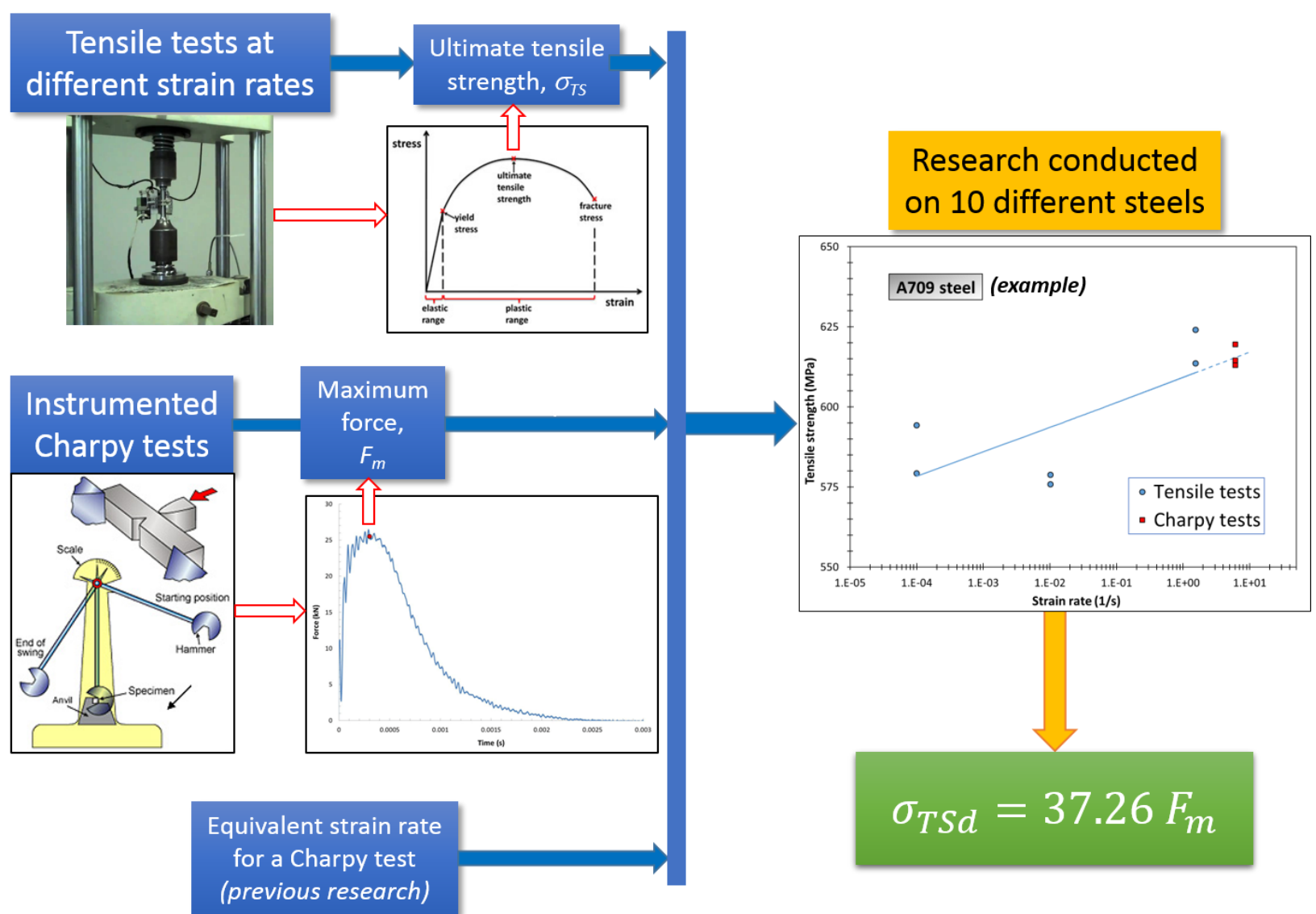

[20] 